Aklin, M., Bayer, P. , Harish, S.P. and Urpelainen, J. (2018) Economics of household technology adoption in developing countries: evidence from solar technology adoption in rural India. Energy Economics, 72, pp. 3546. (doi:10.1016/j.eneco.2018.02.011)

There may be differences between this version and the published version. You are advised to consult the publisher's version if you wish to cite from it.

http://eprints.gla.ac.uk/157934/

Deposited on: 26 February 2018

Enlighten - Research publications by members of the University of Glasgow 


\title{
Economics of Household Technology Adoption in Developing Countries: Evidence from Solar Technology Adoption in Rural India
}

\author{
M. Aklin ${ }^{\mathrm{a}}$, P. Bayer ${ }^{\mathrm{b}, *}$, S.P. Harish ${ }^{\mathrm{c}}$, J. Urpelainen ${ }^{\mathrm{d}}$ \\ ${ }^{a}$ University of Pittsburgh, Department of Political Science, 4814 WWPH, 230 S. Bouquet \\ Street, Pittsburgh, PA 15260, USA \\ ${ }^{b}$ University of Glasgow, School of Social and Political Sciences, Adam Smith Building, 40 \\ Bute Gardens, Glasgow, G12 8RT, Scotland, UK \\ ${ }^{c}$ College of William \& Mary, Government Department, 300 James Blair Drive, \\ Williamsburg, VA, 23185, USA \\ ${ }^{d}$ Johns Hopkins School of Advanced International Studies, Rome Building, 4th floor, \\ 1619 Massachusetts Avenue, NW, Washington, DC 20036
}

\begin{abstract}
Innovation is one of the most important drivers of economic development. Even in developing countries, households have access to a wide array of new technologies. However, factors affecting households' technology adoption decisions remain poorly understood. Using data on solar microgrid adoption from rural India, we investigate the determinants of household technology adoption. We offer all households identical solar products to avoid bias from product differentiation. Households pay a monthly fee for technology use, allowing us to abstract away from credit constraints as a barrier to adoption. The results show that household expenditures and savings as well as the household head's entrepreneurial attitude are strong predictors of adoption. In contrast, past fuel expenditures, risk acceptance, and community trust are not associated with technology adoption decisions. These findings suggest new directions for research on the microeconomics of household technology adoption, which is critical for sustainable development among the poor in developing countries.
\end{abstract}

\footnotetext{
*Corresponding author

Email addresses: aklin@pitt.edu (M. Aklin), patrick.bayer@glasgow.ac.uk (P. Bayer), spharish@wm.edu (S.P. Harish), JohannesU@jhu.edu (J. Urpelainen)
} 
Keywords: technology adoption, solar microgrids, household model, entrepreneurial spirit

JEL: O12, Q42, Q55, Q56

\section{Introduction}

How do households decide on the adoption of new technology? Innovation is one of the most important forces of development (Solow, 1956), and even very poor households now have access to a wide array of new technologies in local markets. However, it is far from clear what makes some households adopt a given technology, but not others. Even when improved household technologies do not directly enhance productivity, they may contribute to higher labor market participation, improved health outcomes and educational attainment (Dinkelman, 2011; World Bank, 2008; Samad et al., 2013). To understand the economics of household technology adoption, we focus on the case of improved household lighting through solar power. Households that do have an electricity connection often have limited hours of access because of poor quality of supply (Aklin et al., 2016). In the absence of grid electricity, households in developing countries often rely on unhealthy and costly alternatives such as kerosene (Lam et al., 2012). When a household decides on adopting new lighting technology, it must compare the costs of the new technology to the benefits from fuel savings and improved lighting quality.

We present a decision-theoretic model that offers an analytical framework to explain household adoption, and generates testable hypotheses. We test these hypotheses against technology adoption data from an impact evaluation study of solar microgrids in rural Uttar Pradesh, India (Aklin et al., 2017). In a random sample of 49 unelectrified habitations (Indian equivalent for hamlets), households were provided an opportunity to subscribe to a solar microgrid service for lighting and mobile charging in exchange for a monthly fee of 100 rupees ( US $\$ 1.5) .{ }^{1}$ Importantly, the technology offered to rural villagers was identical for everyone and the fee-based business model of the technology provider means that we can rule out credit constraints as an explanation for non-adoption by households. ${ }^{2}$ Over a 15 -month period, we

\footnotetext{
${ }^{1}$ Exchange rate of 0.0147 US $\$$ per Indian rupee, as of 20 January 2016.

${ }^{2}$ Indeed, average monthly household expenditure in our baseline survey was 4,339 ru-
} 
surveyed the same households over three waves with the solar microgrids being offered to the households between the first (baseline) and the second (midline) waves. We also conducted a separate service perception survey before the midline.

The results shed new light on the microeconomics of household technology adoption. To begin with, and confirming earlier findings on solar technology adoption (e.g., Rebane and Barham, 2011; Smith and Urpelainen, 2014), affordability through high household income and savings plays an important role in household technology adoption. The results also speak to the role of psychological factors: While risk acceptance is not associated with solar technology adoption in the sample, household heads that score high on an entrepreneurial spirit scale are likely to adopt such household technology. Lastly, our analysis shows that people's adoption decisions are neither associated with their trust in companies and business nor with their trust in other people living in their habitation. Our results are closely related to several key studies in the literature on the economics of technology adoption. Compared to technologies for productive use (Giné and Yang, 2009; Duflo et al., 2011) and learning models (Foster and Rosenzweig, 1995; Bandiera and Rasul, 2006; Conley and Udry, 2010), we focus on household adoption. Given the massive health impacts of indoor air pollution due to kerosene use, the benefits of well-being from efficient cooking and lighting technologies are huge. In addition, and in line with recent works (Suri, 2011; Duflo et al., 2008, 2011), our study demonstrates that when potential adopters have a good understanding of the technology to be adopted, informational barriers are minimal. Instead what matters are the benefits that the technology can offer.

\section{Background Information}

Before presenting the theory, hypotheses, and research design, we briefly describe the fee-based business model that we studied and describe our sample.

\subsection{Technology and Business Model}

The solar power technology under study here is provided by Mera Gao Power (MGP), an Indian company that installs and maintains small solar

pees, so that the service fee amounts to just about $2 \%$ of monthly household spending. 
microgrids in rural Uttar Pradesh. In the firm's business model, individual households can subscribe to an electricity access scheme for a monthly fee of 100 rupees $(\sim \mathrm{US} \$ 1.5) .^{3}$ In exchange, the households receive two bright LED lights and a mobile charger. In this model, MGP generates solar electricity during the day to charge a central battery and then powers the lights and the mobile charger at night, usually from $6 \mathrm{pm}$ until 10 or $11 \mathrm{pm}$ (these hours are controlled by MGP, not individual households), though hours of access are shorter during times of limited insolation, such as the peak of the monsoon and the fog that appears in December/January.

Households within a 100-meter radius of the location of the system (solar panel and batteries) can subscribe to the service. The household connections are designed such that only the lights and the mobile charger can be powered: if households attempt to add other devices, the device disconnects from the central battery. Thus, detecting abuse and non-cooperative behavior by households is relatively easy for MGP staff. An important complication concerns MGP's requirement that at least ten households per habitation need to subscribe to their service before installation is economically feasible. This implies that a single household's willingness to adopt solar power may be insufficient for installation of the microgrid if there is no critical mass of other households who are also interested in the service. ${ }^{4}$

\subsection{Study Sample and Patterns of Technology Adoption}

In India, the 2011 census found that two-thirds of the people (i.e., 400 million individuals) lived in non-electrified households (Government of India, 2011). Among non-electrified households, the most common primary lighting source was kerosene oil, as $31 \%$ of all households (over $90 \%$ of non-electrified households) reported using it as their primary lighting source. Documenting large variation across Indian states, the situation in rural Uttar Pradesh, where our data were collected, is much worse. Only $24 \%$ of households have an electricity connection and three out of four households use kerosene for lighting according to the 2011 census. Barabanki district, where most of our

\footnotetext{
${ }^{3}$ Exchange rate of 0.0147 US \$ per Indian rupee, as of 20 January 2016.

${ }^{4}$ While this does not affect the veracity of our model, our empirical estimation strategy accounts for this complication in two ways. For one, we cluster standard errors in all our models at the habitation level, which is the relevant geographic unit for microgrid installation. Second, we estimate our main models not only for the full sample, but also for the subsample of only those habitations in which MGP microgrids were installed.
} 
study habitations are, has an even lower rural household electrification rate of $14 \%$, as per the same 2011 census.

Our sampling strategy is described in Appendix A1 and basic information on the habitations surveyed is shown in Appendix A3 (Table A6). We conducted a baseline survey (February 2014) before administering treatment (February-July 2017) and followed up with a midline (October 2014) and an endline survey (June 2015) for all households. In August 2014, we conducted a brief summer survey with only those households who had already subscribed to the MGP service at the time. Before MGP offered their solar microgrid to rural villagers in our sample, only 27 out of 778 households in our baseline had access to grid electricity. With only access to electricity for a median number of eight hours and about five power outages during the last 30 days, reliability is poor even among those few with electricity. Household lighting came almost exclusively from kerosene use (96\%), with only $4 \%$ of households reporting battery use to power household lights. The availability of lighting is limited to about five hours of artificial lighting a day. Quality is also poor, as $80 \%$ of households in our baseline survey reported to be either "unsatisfied" or "very unsatisfied" with the quality of lighting.

By the midline survey, 132 households, accounting for about $17 \%$ of our sample, had registered for the MGP service. These numbers decreased to 92 adopters at the time of our endline survey, most likely due to problems for solar microgrids to generate sufficient power during the monsoon and fog seasons in Uttar Pradesh. All adopting households came from 25 out of 49 treatment habitations. ${ }^{5}$

Lighting is not only important for every household, but weekly household expenditures on lighting (29.2 rupees) were more than 3.5 times higher than the money spent on charging mobile phones (7.6 rupees) in our baseline survey. In our summer survey, which was conducted soon after installations, only two out of 136 interviewed households report that better mobile charging was the main reason for subscribing to MGP's service, compared to 134 others emphasizing better lighting. Households apparently consider better lighting as the more important benefit that MGP delivers.

We also have a good understanding of typical household uses of lighting. Table 1 below summarizes key activities, separately for social/non-economic

\footnotetext{
${ }^{5}$ Across survey waves, only 8 households report that they would have liked to adopt, but could not because of insufficient support by other villagers in the habitation.
} 
uses and economic uses, which are primarily intended to generate revenue from selling goods or services in markets. Although not too surprising with only 65 households being business owners in our sample (8.4\%), social and non-business related uses seem to be of much greater importance. By far the most important activities that lighting is used for are cooking (99.9\%), meeting with family (98.5\%), and going out at night (92.4\%).

\section{Social and economic use of lighting from baseline survey (February 2014)}

\begin{tabular}{|c|c|c|c|c|c|c|c|}
\hline \multicolumn{4}{|c|}{ Social/ non-economic activities } & \multicolumn{4}{|c|}{ Economic activities } \\
\hline$\#$ & Activity & HHs (\#) & $\mathrm{HHs}(\%)$ & $\#$ & Activity & HHs (\#) & HHs (\%) \\
\hline 1 & Cooking & $777 / 778$ & $99.9 \%$ & 1 & Home business & $46 / 778$ & $5.9 \%$ \\
\hline 2 & Meeting family & $766 / 778$ & $98.5 \%$ & 2 & Baking for sale & $42 / 778$ & $5.4 \%$ \\
\hline 3 & Going out at night & $719 / 778$ & $92.4 \%$ & 3 & Sale of manufactured goods & $30 / 778$ & $3.9 \%$ \\
\hline 4 & Meeting friends & $621 / 778$ & $79.8 \%$ & 4 & Repair services & $10 / 778$ & $1.3 \%$ \\
\hline 5 & Children studying & $469 / 606$ & $77.4 \%$ & 5 & Handicraft & $3 / 778$ & $0.4 \%$ \\
\hline 6 & Handle livestock & $575 / 778$ & $73.9 \%$ & 6 & Textile decoration & $1 / 778$ & $0.1 \%$ \\
\hline 7 & Studying & $484 / 778$ & $62.2 \%$ & & & & \\
\hline 8 & Reading & $382 / 778$ & $49.1 \%$ & & & & \\
\hline
\end{tabular}

Table 1: The table shows reported use of lighting for social and economic activities from our baseline survey (February 2014) before treatment was administered.

The latter aspect is particularly interesting, as almost $60 \%$ of households who had adopted MGP service reported in the endline interview that outdoor lighting improved, with the accompanying effects of almost a quarter of households saying they spend more time outside at night, more community events are held in the evenings, and almost three out of four households mentioned increased safety at night. This matches findings from a short summer survey which we administered after installations. Table 2 summarizes the results: Here, out of 136 households which had adopted MGP's service by the time of the summer survey, 96 households (70.6\%) report that the primary use of the solar lamps is for outside use, followed by cooking (19\%), children studying $(7.4 \%)$ and reading $(2.9 \%)$.

As emphasized above, microgrid use is not capital-intensive for households, as MGP does not require households to invest in technology itself. However, the monthly service fee that takes away from disposable income for other consumptive uses is by no means a trivial charge, especially outside the harvest season. While it admittedly only accounts for little more than $2 \%$ of household's monthly average expenditures, households in our baseline survey report to spend about 120 rupees for lighting fuels. Drawing on additional 


\begin{tabular}{clrr} 
Lighting uses from summer survey & (August 20 \\
\hline$\#$ & Activity & HHs (\#) & HHs (\%) \\
\hline 1 & Outside use & $96 / 136$ & $70.6 \%$ \\
2 & Cooking & $26 / 136$ & $19.1 \%$ \\
3 & Children studying & $10 / 136$ & $7.3 \%$ \\
4 & Reading & $4 / 136$ & $2.9 \%$ \\
\hline
\end{tabular}

Table 2: The table shows reported lighting use among MGP adopters from a summer survey (August 2014) that was conducted to assess customer experience and satisfaction with the MGP service right after the intervention was completed.

information from our survey data, the primary reason for more than half of the households not having adopted the MGP service is cost. Table 3 shows that the service fee is much more an impediment for adoption than, for example, concerns related to MGP as service provider, alternative solar or battery lighting options, or various other reasons. ${ }^{6}$ Therefore, experimenting with adopting the new technology is by no means costless, but involves a trade-off for each household. Solar lighting is furthermore not a perfect substitute for kerosene, which is also used for cooking and highly subsidized through the public distribution system, biasing against new technology adoption.

\section{Reasons for MGP non-adoption from midline (October 2014) and endline} surveys (June 2015)

\begin{tabular}{llrr}
\hline$\#$ & Reason & N & Share \\
\hline 1 & Cost & 228 & $54 \%$ \\
2 & Problem with MGP & 101 & $24 \%$ \\
3 & Other electricity/lighting option & 62 & $15 \%$ \\
4 & Other reason & 28 & $7 \%$ \\
\hline & Total & 419 & $100 \%$ \\
\hline
\end{tabular}

Table 3: The table shows main reasons reported by households for not having adopted MGP service. Responses come from both the midline (October 2014) and endline surveys (June 2015). Questions were open-ended and we then classified responses by general theme.

In our data, we see about one-third of subscribing households stopping subscription between the midline and the endline, while 'loyal' customers

\footnotetext{
${ }^{6}$ In particular, we do not find any evidence in our survey data that households are biased against adoption because they do not perceive MGP as a caste-neutral provider.
} 
remain satisfied with the service. Table 4 supports this interpretation as the primary reasons for discontinuing MGP service resulted from conflicts with MGP (65\%), e.g., over billing, or the quality of lighting $(27 \%)$. On the one hand, the single most important reason for discontinuation was dissatisfaction with the way MGP conducted the business and interacted with the customers. On the other hand, every fourth customer also complained about lighting quality. Here we note that the foggy season, during which sunlight is reduced to a minimum in December and January, fell between our midline and endline surveys. The reduced availability of electricity at that time could explain why the subscriptions fell between these two survey waves.

Reasons for discontinuation of MGP service from midline (October 2014) and endline surveys (June 2015)

\begin{tabular}{llrr}
\hline$\#$ & Reason & N & Share \\
\hline 1 & Conflict with MGP & 32 & $65 \%$ \\
2 & Quality & 13 & $27 \%$ \\
3 & Cost & 2 & $4 \%$ \\
4 & Conflict with neighbors & 1 & $2 \%$ \\
5 & Other & 1 & $2 \%$ \\
\hline & Total & 49 & $100 \%$ \\
\hline
\end{tabular}

Table 4: The table shows the main reasons given by households for discontinuing the MGP service. Responses come from both the midline (October 2014) and endline surveys (June 2015). Questions were open-ended and we then classified responses by general theme.

\section{Methodology and Research Design}

In this section, we first present a model of household technology adoption in order to motivate and formally derive the hypotheses we test against adoption data from our field experiment. The second part then presents the research design, the econometric model specification, and measurement of key variables.

\subsection{Model of Household Technology Adoption}

Our model focuses on technology adoption of an individual household. Specifically, we consider the adoption decision of a solar microgrid as a means to power household lighting from a renewable energy source. The baseline model characterizes a household's energy demand when only kerosene is 
available as a lighting fuel. In the literature on household energy, the household can thus be thought of as reaching the first step of the "energy ladder" (Masera et al., 2000; Cheng and Urpelainen, 2014). In a second step, we then compare this baseline demand to a case when solar microgrids are added to the household's choice set as a renewable energy alternative. Finally, we extend the model further to account for the importance of community trust in the adoption of network resources, such as community solar microgrids. Comparative statics are derived from equilibrium energy consumption for household lighting.

\subsubsection{Baseline Model of Kerosene Consumption}

Following the literature on solar technology adoption (e.g., Komatsu et al., 2011; Smith and Urpelainen, 2014), the household chooses optimal consumption levels of kerosene $k$ as an energy source and a numeraire good $n$. Market prices for these goods are denoted $p^{k}$ and $p^{n}$, respectively, and the household is assumed to be a price taker. As usual, only relative prices matter, so we normalize the numeraire price to $p^{n}=1$.

Given our interest in household lighting technology adoption, a household is not interested in kerosene consumption per se, but in the lighting output that kerosene use generates. We model lighting output $l$ as

$$
l(k)=\alpha f(k),
$$

where $\alpha>0$ is an efficiency parameter of lighting production and $f$ is an increasing, strictly concave, and smooth function. Household lighting output has decreasing returns to scale.

Further, let the household's objective function $U$ be given as

$$
U=\sum_{i \in \mathcal{I}} B_{i}(l ; \mathbf{h})-\sum_{j \in \mathcal{J}} H_{j}(k ; \mathbf{h})+n .
$$

Lighting benefits are captured by $B_{i}$, which are increasing, strictly concave, and well-behaved functions over the set of benefits $\mathcal{I}$. Since artificial lighting at night is a critical input for productive household activities in many developing countries' rural communities, profits from these activities are an explicit element of the sub-utilities $B_{i}$; when a household runs a business, we could have $B_{i^{\prime}}=\Pi(l ; \cdot)$ with $i^{\prime} \in \mathcal{I}$, where $\Pi$ denotes household profits.

Functions $H_{j}$ are also increasing and well-behaved, but strictly convex in $k$, as they capture the negative effects from kerosene use, like indoor air 
pollution. Vector $\mathbf{h}$ denotes a set of household characteristics, for instance, household size, and all functions $B_{i}$ and $H_{j}$ are increasing in every single element of $\mathbf{h}$. Benefits from lighting are (local) public goods for household members, while damages from kerosene use are household public bads, so that this simplifying assumption is plausible.

Given a household's budget constraint $p^{k} k+n=X$, optimal kerosene and numeraire consumption levels $k^{*}$ and $n^{*}$ are implicitly characterized in equilibrium by the following two first-order conditions: ${ }^{7}$

$$
\sum_{i \in \mathcal{I}} \frac{\partial B_{i}(l ; \mathbf{h})}{\partial l} \alpha f^{\prime}(k)-\sum_{j \in \mathcal{J}} \frac{H_{j}(k ; \mathbf{h})}{\partial k}-p^{k}=0 \quad \text { and } \quad n^{*}=X-p^{k} k^{*} .
$$

\subsubsection{Model with Solar Power Technology}

In the extended model in which a household can choose to adopt solar power for household lighting, lighting output depends on kerosene input $k$ and solar power input $\bar{s}$, so that

$$
l(k, A)=\alpha f(k)+\beta \bar{s} \mathbb{I}(A=1),
$$

where $\beta>0$ is a strictly positive efficiency parameter and $\mathbb{I}$ is an indicator function which scores one whenever the household adopts solar power, $A=1$; the lighting production function reduces to equation (1) if the household continues to exclusively rely on kerosene for home lighting. Notably, $\bar{s}$ is a fixed quantity determined by the output generated from the solar microgrid, so that households demanding lighting output $l>l(k=0, A=1)$ are going to still consume a positive quantity of kerosene even after adopting solar power. This is a distinctive feature of solar microgrids, which typically cannot meet a household's entire energy need and do not produce enough electricity for productive loads.

The literature on solar technology adoption highlights asymmetric information as a key issue (Rebane and Barham, 2011; Bollinger and Gillingham, 2012; Lay et al., 2013; Smith and Urpelainen, 2014; Urpelainen and Yoon, 2015). As solar power is a new technology to villagers, we assume incomplete information about the efficiency parameter $\beta$ from a distribution function $F$ with positive support $[\beta, \bar{\beta}]$ and standard deviation $\sigma_{\beta}$ such that

$$
\sigma_{\beta}=\bar{\sigma}+\sigma(N ; \bar{N})
$$

\footnotetext{
${ }^{7}$ The third first-order condition from the quasi-linear Lagrangian is simply $\lambda=1$.
} 
Here, $\bar{\sigma}$ denotes individual-specific, idiosyncratic uncertainty which always persists, while $\sigma(N ; \bar{N})$ captures the variability in $F$ which is decreasing as a function of the number of other adopting households $N ; \bar{N}$ is then a technology-specific number of adopters needed to drive this component of household uncertainty to zero, as a result of learning (Foster and Rosenzweig, 1995; Bandiera and Rasul, 2006; Conley and Udry, 2010). ${ }^{8}$

To account for the possibility that households in rural villages may decide to start their own business once solar power becomes available, we again model potential business profits $\Pi$ as part of the expected utility stream a household obtains from lighting $l$. As before, where profits for existing business owners are simply modeled as an additional component in a household's benefit stream, the difference between a household that anticipates to take up a business and who does not would again be the size of the benefit set $\mathcal{I}$ over which sub-utilities are added up. For any given set $\mathcal{I}$ prior to solar adoption, a household's set of sub-utilities could be written as $\{\mathcal{I}\} \cup\left\{i^{\prime}\right\}$ with $B_{i^{\prime}}=\Pi(l ; \cdot)$ when a household expects to start its own business, increasing the cardinality of the new, union set by one. Taking up a business because of better access to solar lighting through solar microgrids, in our model, can simply be accounted for by extending the set of benefits from lighting. All else equal, the expectation of future profits from business ownership hence provides households with one more benefit component over the aggregated benefit stream when they calculate total expected utility from technology adoption.

Recognizing uncertainty about the efficiency of solar lighting through microgrids, as captured by $\beta$, a household's expected utility function when adopting solar power is given as

$$
\mathbb{E}[U]=\int \sum_{i \in \mathcal{I}} B_{i}(l ; \mathbf{h}) d F(\beta)-\sum_{j \in \mathcal{J}} H_{j}(k ; \mathbf{h})+n .
$$

Keeping the notation from above and given a household's modified budget constraint $p^{k} k+p^{s}+n=X$, where $p^{s}$ denotes the adoption fee for solar

\footnotetext{
${ }^{8}$ Technically, we have $\sigma \rightarrow 0$ if $N \rightarrow \bar{N}$. Even though we will not be able to test this particular aspect of the model because we have too few time periods in our panel data set, our theoretical model is more general and would allow modeling learning dynamics in household technology adoption. Since $\bar{N}$ varies with technology, the model can produce equilibrium predictions for technology adoption for more than two alternatives.
} 
power, which is a fixed cost and thus independent of the amount of solar power consumed, the following two implicit functions characterize optimal levels of kerosene and numeraire consumption $\hat{k}$ and $\hat{n}$ when a household decides to adopt solar power: ${ }^{9}$

$$
\sum_{i \in \mathcal{I}} \mathbb{E}\left[\frac{\partial B_{i}(l ; \mathbf{h})}{\partial l}\right] \alpha f^{\prime}(k)-\sum_{j \in \mathcal{J}} \frac{\partial H_{j}(k ; \mathbf{h})}{\partial k}-p^{k}=0 \quad \text { and } \quad \hat{n}=X-p^{k} \hat{k}-p^{s}
$$

\subsubsection{Model with Solar Power Technology and Community Trust}

A distinctive feature of solar microgrids in our context is the community aspect of technology adoption. Solar power can only effectively be provided if none of the households - be they adopters or non-adopters - overuses the community grid, steals electricity, or tampers with the wiring of the system. Moreover, the potential adopters must consider the service provider's trustworthiness regarding service and payments. Solar microgrids are a prime example of what is considered a collective good (Olson, 1965; Cornes and Sandler, 1986) with network characteristics (Katz and Shapiro, 1985). Although the consumption of solar lighting does not require active cooperation, each subscriber and non-subscriber must refrain from behaving in a way that would prompt the service provider to exit the market.

Given this dilemma, after adoption and upon payment of the service fee, the benefits from solar power do not accrue with complete certainty. Instead, benefit streams depend on each household's beliefs about the "trustworthiness" (Coleman, 1988; Hardin, 2002) of the company providing the service and other people in the community. This trust parameter $\theta \in[0,1]$ scales expected benefits and is assumed to be exogenous and household-specific. It is best thought of as a Bayesian prior, that is, as a household's subjective probability on a state of the world in which other households in the community would engage in any activity that puts uninterrupted and continuous provision of solar power at risk. Low levels of community trust could thus bias against technology uptake as adoption becomes a riskier choice due to less certain benefits.

Although this requires only a slight change in the household's objective

\footnotetext{
${ }^{9}$ As before, the third first-order condition yields $\lambda=1$ because of the quasi-linearity in the Lagrangian.
} 
function

$$
\mathbb{E}[U]=\theta \int \sum_{i \in \mathcal{I}} B_{i}(l ; \mathbf{h}) d F(\beta)-\sum_{j \in \mathcal{J}} H_{j}(k ; \mathbf{h})+n,
$$

the modification breaks new ground in two important ways. Theoretically, it helps generalize our setup to account for network resources. Empirically, it allows us to model technology adoption as a function of household-level prior beliefs about community trust.

\subsubsection{Optimal Technology Adoption}

In equilibrium, optimal technology adoption $A^{*}$ for a household is determined by the following decision rule

$$
A^{*}= \begin{cases}1 & \mathbb{E}[U(\hat{k}, \hat{n} ; \theta)]>U\left(k^{*}, n^{*}\right) \\ 0 & \text { otherwise }\end{cases}
$$

where the new technology is adopted if and only if the expected utility from the optimal consumption profile $(\hat{k}, \hat{n})$ under solar power adoption is strictly larger than the utility from the consumption of equilibrium levels of kerosene and the numeraire $\left(k^{*}, n^{*}\right)$ without adopting solar power.

So far, we have shown that households consume kerosene in both cases up to levels at which (expected) marginal benefits net of marginal costs equal exogenous market prices $p^{k}$. A household's adoption decision then depends on four effects: a substitution effect, an uncertainty effect, a consumption effect, and a trust effect.

The substitution effect captures reductions in kerosene use after a household adopts solar power adoption. This reduction results from the fact that the same equilibrium lighting output without solar microgrids $l^{*}$ can now be generated with strictly less kerosene input than before. Since kerosene use is hazardous, substitution away from it confers utility to the household from solar power adoption. The uncertainty effect comes from households not knowing the efficiency parameter $\beta$ for sure, which stacks the deck against adoption of solar power due to the concavity in household utility. The consumption effect arises from the need to possibly give up some consumption of the numeraire $n^{*}$ if the reduction in kerosene use due to solar power adoption does not free up enough of a household's budget to fund the fixed fee of the microgrid $p^{s}$. Finally, the trust effect matters for technology adoption as a household's prior belief about community trust affects the probability with which benefits from solar power materialize. 


\subsubsection{Comparative Statics}

Here we derive comparative statics for four different quantities of interest: changes in the budget constraint, in a household's business activity, in uncertainty about the efficiency of solar technology, and in community trust. These are presented and discussed in turn to formulate testable hypotheses for the empirical analysis.

Budget constraint: As we assume a household's utility function to be quasi-linear, optimal consumption levels of kerosene $k$ are independent of the budget. By implication, relaxing the budget constraint leaves kerosene consumption unaffected, so that a non-adopting household continues to consume $k=k^{*}$ as long as this consumption level can be funded $\left(X \geq p^{k} k^{*}\right)$ and remains the utility-maximizing choice even in the case of a corner solution, i.e., $U\left(k^{*}, 0\right)>U\left(0, n^{*}\right)$.

Still, higher disposable income to fund the new technology makes adoption of solar power more likely, at least if the increase in utility from adoption per unit of money spent outweighs the increased utility from consuming the numeraire good. As the return in per money units spent from numeraire consumption is always one, solar power adoption becomes more likely when the following inequality holds:

$$
\frac{\sum_{i \in \mathcal{I}} \theta \mathbb{E}\left[B_{i}\left(\alpha f\left(k^{*}\right)+\beta \bar{s} ; \mathbf{h}\right)\right]-\sum_{i \in \mathcal{I}} B_{i}\left(\alpha f\left(k^{*}\right) ; \mathbf{h}\right)}{p^{s}}>1
$$

At this level of generality, assessing whether this condition is met is impossible and depends on the specific application. However, in our case, where we assume households to be energy poor, it seems reasonable that even small increases in access to lighting have (comparatively) strong effects in the utility response function; this is particularly so, given the concave nature of sub-utilities $B_{i}$. Similar to earlier studies (Jacobson, 2007; Lay et al., 2013; Smith and Urpelainen, 2014), we thus expect to find empirical support for the following hypothesis:

\section{Hypothesis 1 (Adoption and budget constraint).}

Richer households with less binding budget constraints are more likely to adopt new technology in the form of solar microgrids, if offered.

Business activity: No matter whether a household already engages in business activity prior to technology adoption or whether a household 
envisions to start its own business after new lighting technology becomes available, in both cases the set of household benefits, defined as the union set $\mathcal{B} \equiv \cup_{i} B_{i}$, for such a household is strictly larger than for an otherwise comparable household who does not run its own business. The demand for lighting $l$ is thus increasing in the cardinality of $\mathcal{B}$. As adopting solar power can increase lighting output to meet higher demand, while at the same time not driving up hazardous damages as kerosene would, solar adoption becomes more likely for households already running or planning to run their own business, that is, for households with strong entrepreneurial spirit. We will test this hypothesis against our data of solar power adoption in rural India.

\section{Hypothesis 2 (Adoption and business activity).}

Households already running a business or entrepreneurial households aspiring to do so are more likely to adopt new technology in the form of solar microgrids, if offered.

Risk aversion: Lighting output $l$ from solar power depends on the efficiency parameter $\beta$, which is unknown to households as $\beta \sim F_{[\underline{\beta}, \bar{\beta}]}\left(\mu_{\beta}, \sigma_{\beta}\right)$. Adopting solar power is therefore a risky choice. We further assumed that lighting benefits $B_{i}$ are strictly concave and additive in $\mathbb{E}\left[\sum_{i \in \mathcal{I}} B_{i}(l ; \mathbf{h})\right]$; households are hence risk averse in lighting benefits, which biases against solar power adoption. This allows formulating the following hypothesis.

\section{Hypothesis 3 (Adoption and risk aversion).}

Less risk averse households are more likely to adopt new technology in the form of solar microgrids, if offered.

Community trust: With solar microgrids being a network resource, the likelihood with which benefits from solar power adoption materialize depends on a household's individual expectation about other households' behavior. For high levels of community trust, $\theta$ takes on high values and drives up expected benefits from technology adoption. We thus expect a positive relationship between community trust and adoption of solar microgrids.

\section{Hypothesis 4 (Business and community trust).}

Households with more trust in their community are more likely to adopt new technology in the form of solar microgrids, if offered. 
Kerosene market prices: Kerosene market prices $p^{k}$ are exogenously given and rural households are assumed price takers. As market prices increase, the derived first-order conditions in equations (3) and (7) no longer hold. Households then adjust their consumption behavior by reducing the amount of kerosene consumed, which brings down the summed damages $\sum_{j \in \mathcal{J}} H_{j}(k ; \mathbf{h})$, but also summed (expected) benefits from lighting. However, because of the convexity and concavity assumptions, respectively, damages decrease more quickly than benefits, balancing the first-order conditions again. Reductions in kerosene consumption for non-adopting households must always be larger than for households already using solar power as solar mircogrids offer an alternative lighting source. This has to be so as households with solar mircogrids use strictly less kerosene to begin with. To obtain output $\bar{l}$, for example, non-adopting households consume $k=f^{-1}\left(\frac{\bar{l}}{\alpha}\right)$, while adopting households only require $k=f^{-1}\left(\frac{\bar{l}-\beta \bar{s}}{\alpha}\right)$, which is strictly smaller. Reducing consumption levels from $k$ to $\bar{k}$, requires thus less adjustment by households already using the new technology. If, however, upon spiking prices in kerosene markets, non-adopting households were to reduce consumption and, as a consequence, lighting output, too, this is when adopting solar mircogrids becomes more attractive. This underlies why price increases in kerosene markets make the adoption of solar mircogrids more likely, which we also test below.

\section{Hypothesis 5 (Adoption and kerosene market prices).}

Increases in kerosene market prices make households more likely to adopt new technology in the form of solar mircogrids, if offered.

\subsection{Research Design}

To test the model, we use original data from a field experiment with distributed solar power in rural Uttar Pradesh, India (Aklin et al., 2017). While the goal of the field experiment was to evaluate the impacts of distributed solar power, here we use data on adoption behavior in habitations that were offered access $(N=49)$ to household electricity through solar microgrids. The study was conducted in three waves over the course of almost one year from September 2014 to June 2015 (see Appendix A1 for details). As in our formal model above, the unit of analysis is a household in a survey wave. We estimate both panel and cross-sectional models (by survey) to predict adoption rates of solar power for household use. In total, our sample comprises a 
maximum of 765 households in the midline and 777 households in the endline survey, from 49 different habitations. ${ }^{10}$ We estimate logistic regressions and linear probability models to explain household adoption decisions of solar technology.

By focusing on the adoption of solar power provided through MGP microgrids in the context of a controlled randomized trial, our empirical analysis benefits from several advantages. First, and most important, we can measure the dependent variable of technology adoption accurately, which ensures comparability of household decisions. Second, the experimental nature of the study minimizes possible contamination which could result, for instance, from households being offered access to other or similar forms of solar technology from competing providers. Third, our initial baseline survey, which was conducted pre-treatment in February 2014, reveals that $96 \%$ of all households in our sample use kerosene lamps for household lighting. This is key as once MGP started offering households access to solar microgrids, the adoption decision that households needed to make (as in our formal model above) was truly dichotomous. Fourth, offering energy-deprived households an alternative form of household lighting makes for a very real adoption choice; this decision impacts everyday lives, and so rural villagers are likely to seriously consider this offer, making revealed behavior meaningful. ${ }^{11}$ Finally, the empirical analysis, to our knowledge, is the first to study technology adoption of energy by individual households for its social benefits rather than technology adoption of, for example, new fertilizers by rural farmers to increase agricultural yields.

\subsubsection{Model Specification}

In our empirical analysis, we estimate logistic panel regressions:

$$
\operatorname{Logit}\left(Y_{i t}\right)=\alpha+\beta X_{i, p r e}+\varepsilon_{i t},
$$

where for household $i$ and survey wave $t=\{$ midline, endline $\}, Y_{i, t}=\{0,1\}$ is a time-varying indicator variable for whether a household had subscribed to the MGP service or not. The household-specific vector of covariates $X_{i, p r e}$

\footnotetext{
${ }^{10}$ In the field experiment we tried to offer solar power to 54 habitations, but in five of them flooding prevented us from doing so. Because households in these households could not adopt even if they wanted, these habitations are excluded from the study sample.

${ }^{11}$ Only 27 households out of 778 (about $3.5 \%$ ) in the baseline survey report to have a grid connection.
} 
is measured pre-treatment during our baseline survey to avoid simultaneity bias; $\alpha$ denotes the intercept, $\beta$ captures the vector of slope coefficients, and

$\varepsilon_{i t}$ is the error term. As households live in different habitations, we cluster standard errors at the habitation level.

To show the robustness of our main results, we estimate panel regressions also as linear probability models (Appendix A5), separately for midline and endline cross-sections (Appendix A6), models with village-level fixed-effects (Appendix A7), and conduct subsample analyses(Appendix A8), without substantial changes to our results.

\subsubsection{Dependent Variable}

The dependent variable is a binary indicator for whether household $i$ is subscribing to the MGP service at time $t$. During the time of the baseline survey, in which we collected a battery of household data, no household had access to this service. This is important as it safeguards our analysis against confounding, and hence allows us to use these baseline data as pre-treatment covariates.

\subsubsection{Main Explanatory and Control Variables}

We differentiate our main models below by the set of explanatory variables which we include. The first model only includes basic indicators of disposable income and wealth. More specifically, we include measures from our survey on household expenditures and household savings, both measured in rupees per month; we logarithmize both variables to account for the skewed distribution income variables typically have. We also add a dummy variable on whether a household is indebted or not.

As a second set of variables, we include a variable for how entrepreneurial a household is, a binary indicator for business ownership, and a measure for revealed risk aversion. We measure entrepreneurial spirit as an additive index of responses to the following eleven true-false questions: I am at ease handling difficult situations; I do not mind uncertain monthly income; I do not irregular monthly income; I believe that I can change my own future; I appreciate having the final say; I do not have a problem making decisions; I can easily deal with stress; I am willing to make sacrifices to succeed; I like to lead others; I am not scared starting anew; I get difficult tasks done rather now than later. We consider entrepreneurial spirit as a latent trait of an individual, such as a household head, that is related but not identical to risk acceptance. Drawing on Schumpeterian insights into the role of entrepreneurs 
and "creative destruction" in capitalist economies (Schumpeter, 2003 [1943]), the literature on entrepreneurship finds this latent trait to be an important predictor of engagement in business creation, and thus creating economic growth (Doepke and Zilibotti, 2005; Galor and Michalopoulos, 2012). In our baseline sample, households reporting an interest in opening a business in the future (about $60 \%$ of our sample) score significantly higher on our entrepreneurial spirit index than household heads without such interest (6.75 to 5.66 , with $t=6.086)$.

Business ownership is a simple dummy variable coded one whenever a household runs its own business. In our baseline data, less than $10 \%$ of households were running their own business. ${ }^{12}$ These households also score higher in terms of entrepreneurial spirit than those who run a business only part-time, but business owners as a whole are comparable to households without their own business. ${ }^{13}$ Important for our purposes, only two households work at night, and both agree that better lighting would help their business, which suggests that lacking access to lighting limits households' economic productivity and output.

We measure risk aversion from a choice experiment which we conducted as part of our survey. We prompted survey responses with the hypothetical choice between a payment of 3,000 rupees for sure and a lottery with expected values of 3,250 rupees, 3,500 rupees, and 4,000 rupees, respectively, where we increased the expected offer for those households which would reject the safe option. We then use reported behavior to these choices to classify households on a 1-4 scale from risk loving to very risk-averse; higher values denote more risk aversion. While several approaches on how to elicit risk aversion exist (Holt and Laury, 2002), survey-based menus of hypothetical paired choices have a long tradition, especially in the context of development economics (Dillon and Scandizzo, 1978). Most important for our context, almost a third of households in our sample can be classified as risk loving, which

\footnotetext{
${ }^{12}$ Out of 65 business owners, two-thirds were active in selling goods in markets, while ten were active in dairy and cooking, five in the repair business and another five in handicraft and textiles. On average, business activity accounts for $46 \%$ of household income, while 29 households report that their own business is the main source of income.

${ }^{13}$ The small number of business owners limits further analysis, but descriptively the entrepreneurial spirit variable is 5.66 (part-time business owners) and 6.03 (main income business owners) and 5.83 (business owners) and 6.31 (no business owners). None of these differences are statistically significant in two-tailed t-tests.
} 
alleviates the typical concern of over-representing risk aversion in reported over revealed behavior measures (Binswanger, 1980). Acknowledging that comparing measures of risk aversion is beyond the scope of this paper, we primarily introduce our measure of risk aversion as an explanatory variable into our econometric model as we seek to tease out differences in adoption behavior due to household entrepreneurship and risk aversion. As Guiso and Paiella (2008: 1109) find that individuals "who are more likely to face income uncertainty ... exhibit a higher degree of absolute risk aversion," separating these two influences on technology adoption seems well founded.

To test our expectations about community trust, we use two trust measures from our survey. In our theoretical model, community trust affects the likelihood with which a household expects to obtain benefits from adopting solar microgrids. Interestingly for our empirical application, we can distinguish between targets of trust. For one, households may be concerned about the trustworthiness of other households in the habitation, which makes adoption of the new technology less attractive. On the other hand, households may also be concerned about the trustworthiness of the service provider, that is, the business which operates the new technology. In our case, if households do not trust MGP, they should be less likely to adopt MGP's solar powered microgrids. To empirically test for these differences, we construct two indices, both on a 1-5 scale with higher values denoting "more trust." The first index averages household responses to questions related to general trust in people in the habitation and trust in people from the same religion and caste as well as from another religion and caste. ${ }^{14}$ The second index records the mean of household responses for trust in large companies, small firms, and local enterprises to capture household trust towards firms. ${ }^{15}$ As we are not sure whether households think of MGP as a large, a small, or a local firm, averaging responses produces the most reliable measure.

Extending the set of variables further, we include variables for previous lighting solutions at home. These entail the monthly amounts of rupees

\footnotetext{
${ }^{14}$ Specifically, we asked the following five questions for trust in people: (1) Do you trust the other people in your hamlet? (2) Do you trust people of other religion? (3) Do you trust people of your religion? (4) Do you trust people from your own caste? (5) Do you trust people from other castes?

${ }^{15}$ The three questions for trust in firms were as follows: (1) Do you trust large companies? (2) Do you trust small companies? (3) Do you trust companies operating in this area?
} 
spent (logged) for buying kerosene both from the public distribution system (PDS), where prices are highly subsidized, and the private (black) market (Rao, 2012). Controlling for kerosene expenditures is critical as kerosene is typically the primary lighting source in rural communities; in fact, $96 \%$ of households in our sample are using it for their lighting at home. Kerosene on the public, subsidized market is cheaper, but households can only obtain fixed amounts which are rarely sufficient to cover a household's full lighting demand. A vast majority of $85 \%$ of households buy kerosene from the PDS, spending about 37 rupees a month, but also from the private market, where expenditures, on average, are almost twice as high. As efficient lighting technologies, like solar microgrids, are to reduce the need to supplement kerosene from the public distribution system, we expect households with high kerosene bills from the private market to be sympathetic to technology adoption.

An electrification dummy controls for whether households have already access to some form of electricity (including lighting amongst other forms of electricity access) as this clearly affects adoption behavior of the solar microgrid. As mentioned before, only $4 \%$ of households in the sample reported to have electricity access in the baseline interview.

Finally, variables of household characteristics and subjective perceptions are included. We control for the number of household members to account for household size, the age of the household head, the household head's number of school years, and two dummy variables for whether a household head is from a scheduled or backward caste, mainly because previous research has shown that these variables affect technology adoption (Bandiera and Rasul, 2006; Giné and Yang, 2009; Koundouri et al., 2006). Aside from these household characteristics, perceptional measures are added to some of our model specifications. Adesina and Zinnah (1993), for example, show that farmers' perceptions of technology specific attributes are critical for understanding adoption decisions of rice varieties in Sierra Leone. This is in line with psychological research, which also attests to the importance of attitudes towards technologies (Morris and Venkatesh, 2000). We hence control for lighting satisfaction and perceived benefits from solar power. These data come specifically from survey questions on (i) how satisfied the household is with its current lighting situation (5-point scale) and (ii) whether (or not) a household agrees to the statement that solar power can decrease monthly lighting expenditures (0-1 measure).

Summary statistics of all explanatory variables for the full sample are 
in Table 5 below, while we report summary statistics separately by installation and adoption status in Appendix A3. Table 6 shows trends in means for main, time-varying variables for the three different surveys. When comparing pre-treatment summary statistics from our baseline survey, we find habitations that ultimately ended up subscribing to MGP's service to spend significantly less on kerosene from the PDS (32.68 vs 42.37 rupees, $t=4.60$ ), but significantly more on kerosene from private markets (77.60 vs $65.40 \mathrm{ru}-$ pees, $t=2.66$ ); this aligns well with the logic discussed above. Household heads in habitations with installed MGP service are also almost two years older (39.6 vs 37.7 years, $t=2.04$ ), have almost one year less education $(2.42$ vs 3.34 years, $t=3.13)$ compared to habitations without solar microgrids, and are more likely to come from a backward caste (0.68 vs $0.58, t=2.86$ ).

\begin{tabular}{lccccc}
\multicolumn{5}{c}{ Summary statistics } \\
\hline & Mean & SD & Min & Max & $\#$ \\
\hline HH expenditures (rupees/month, log) & 8.24 & 0.54 & 6 & 10 & 778 \\
HH savings (rupees/month, log) & 4.47 & 3.37 & 0 & 9 & 778 \\
HH in debt & 0.49 & 0.50 & 0 & 1 & 778 \\
Entrepreneurial spirit & 6.27 & 2.45 & 0 & 11 & 778 \\
Business owner & 0.08 & 0.28 & 0 & 1 & 778 \\
Risk aversion (experiment) & 2.69 & 1.31 & 1 & 4 & 778 \\
Trust in people (index) & 3.55 & 0.79 & 1 & 5 & 778 \\
Trust in firms (index) & 2.98 & 1.13 & 1 & 5 & 778 \\
Kerosene spending (PDS, rupees/month, log) & 3.17 & 1.35 & 0 & 6 & 778 \\
Kerosene spending (private, rupees/month, log) & 3.30 & 1.99 & 0 & 6 & 778 \\
HH electrification & 0.03 & 0.18 & 0 & 1 & 778 \\
HH size (\#) & 4.79 & 2.13 & 1 & 12 & 778 \\
Age of HH head & 38.70 & 13.27 & 18 & 82 & 778 \\
School years of HH head & 2.87 & 4.14 & 0 & 17 & 778 \\
Scheduled caste & 0.25 & 0.43 & 0 & 1 & 778 \\
Backward caste & 0.64 & 0.48 & 0 & 1 & 778 \\
Lighting satisfaction & 1.96 & 0.83 & 1 & 5 & 778 \\
Solar power decreases lighting cost & 0.76 & 0.43 & 0 & 1 & 778 \\
\hline
\end{tabular}

Table 5: Summary statistics for main variables. All variables are measured pre-treatment and come from the baseline survey (February 2014). Non-logged means in US\$ with an exchange rate of 0.0147 US $\$$ per Indian rupee, as of 20 January 2016, are $\$ 63.79$ (HH expenditures), \$12.68 (HH nominal savings), \$0.55 (PDS kerosene spending), and \$1.05 (private market kerosene spending).

Within habitations that adopted MGP service, adopting households have higher monthly household expenditures of about 450 rupees (8.31 vs 8.19 
(logged) rupees, $t=2.08$ ) and save about $120 \%$ more per month (5.11 vs 4.32 (logged) rupees, $t=2.22$ ). They are also more entrepreneurial, with scores of 6.60 over 5.90 on a 0 - 11 scale $(t=2.81)$, hold more positive views of solar power in terms of the technology's potential to reduce monthly lighting expenses (0.84 vs $0.73, t=2.48)$, and more likely to come from a backward caste $(0.74$ vs $0.65, t=1.96)$

Summary statistics by survey

\begin{tabular}{lccc}
\hline & $\begin{array}{c}\text { Baseline } \\
\text { February } 2014\end{array}$ & $\begin{array}{c}\text { Midline } \\
\text { October 2014 }\end{array}$ & $\begin{array}{c}\text { Endline } \\
\text { June 2015 }\end{array}$ \\
\hline HH expenditures (rupees/month, log) & 8.23 & 8.06 & 8.04 \\
HH savings (rupees/month, log) & 4.46 & 1.88 & 1.93 \\
HH in debt & 0.49 & 0.46 & 0.54 \\
Business owner & 0.08 & 0.06 & 0.06 \\
Trust in people (index) & 3.54 & 3.65 & 3.75 \\
Trust in firms (index) & 2.97 & 3.41 & 3.38 \\
Kerosene spending (PDS, rupees/month, log) & 3.16 & 2.98 & 3.38 \\
Kerosene spending (private, rupees $/$ month, log) & 3.29 & 2.13 & 1.57 \\
HH electrification & 0.03 & 0.39 & 0.41 \\
Lighting satisfaction & 1.96 & 3.30 & 3.40 \\
Solar power decreases lighting cost & 0.76 & 0.81 & 0.72 \\
\hline
\end{tabular}

Table 6: Mean values of main variables by survey, separately for baseline (February 2014, $N=778$ ), midline (October 2014, $N=765$ ), and endline surveys (June 2015, $N=777$ ).

\section{Results}

In this results section, we first discuss descriptive findings that show how many key variables of interest change over the duration of the study periods. We then present our econometric results for household solar microgrid adoption.

\subsection{Descriptive Findings}

Overall, 136 households adopted the MGP service. Of these, 132 reported being customers in our first post-treatment interviews, and 4 more had joined when we conducted our last survey. Between the second and third wave, 47 households canceled their contract with MGP.

Adopters and non-adopters differed in several respects. Table 7 reports summary statistics separately for adopters and non-adopters, both pre- and 
post-treatment. Adopters were wealthier and had more savings. They had a stronger entrepreneurial spirit and spent more on kerosene on the private market. At the same time, based on these simple differences, we also note that the two groups were also similar in important ways: a similar share of people owned businesses, their household head was about the same age, and they were about equally satisfied about their lighting situation. To provide a more precise analysis of these differences, we next discuss our econometric results.

The before-after comparisons by group reveal a two notable temporal trends. First, household monthly savings decrease in both groups over time, possibly because the fiscal year 2014-2015 was particularly bad one for Uttar Pradesh agriculture. Second, overall electrification rates increase from $3 \%$ to $31 \%$ even among non-adopters, mostly because use of both non-MGP solar products and batteries grows rapidly.

\subsection{Econometric Results}

The results from the panel data analysis are shown in Table 8, with models differentiated by the set of included covariates. Models (1)-(4) use household-level adoption data from all 49 habitations, in which MGP service was offered. Due to low demand, microgrids were however not installed in all habitations, so models (5)-(8) replicate the analysis for habitations in which a microgrid was indeed installed.

Estimating models with habitation fixed effects is only partially useful in our setting, because we would lose all those habitations where either (i) no MGP system was installed (24 habitations) or (ii) we did not end up having at least one adopting household in our sample of interviewed respondents. ${ }^{16}$ The latter was the case for five out of 25 habitations and dropping these observations would clearly bias our results. Nonetheless, to reduce unobserved heterogeneity across habitations, in models (5)-(8) we re-estimate our main models for the subsample of only those 25 habitations in which MGP microgrids were installed.

All coefficients are given as odds-ratios and capture the effect of a variable on the probability of technology adoption relative to the probability of nonadoption. Accordingly, we test whether the odds-ratio (i.e., exponentiated

\footnotetext{
${ }^{16}$ Appendix A3 (Table A6) provides further information on installation and adoption rates by habitation.
} 
coefficient) is equal to 1 . This translates into adoption and non-adoption being equally likely, which is identical to an estimated coefficient of zero in standard coefficients. The simple monotone transformation from standard coefficients into odds-ratios makes the substantive interpretation of coefficients in non-linear logistic regressions much easier.

Focusing on the full sample first, which includes both habitations that adopted MGP solar microgrids and those in which there was no installation because of lacking demand, we find strong empirical support for our first hypothesis. Richer households are indeed more likely to adopt solar power, and at highly statistically significant levels ( $p<0.05$ throughout all models). Using monthly household expenditures and savings as measures for disposable income, we find that doubling these two variables increases the odds (ratio of success to failure) of technology adoption (holding all variables at their means) by 129-159\% for household expenditures and by $19-23 \%$ for increases in savings.

This finding hints at critical income and wealth effects for household adoption of new technology. While similar effects have been found for the adoption of sunflower seeds or new irrigation systems (Bandiera and Rasul, 2006; Koundouri et al., 2006), adoption of household lighting technology compared to these more productive uses may also be impeded by budget constraints. Somewhat surprisingly, income and wealth effects occur even though households should be able to recoup the MGP service fee of 100 rupees by saving a substantial share of their expenses on lighting, which are reported to amount on average to 116 rupees per month on average. Most likely, however, MGP services alone cannot cover a household's full lighting demand. Since MGP offers two lights, a large family may need additional lighting; moreover, households may continue to use a kerosene lantern when going outside, as the MGP lights are not wireless. Given low correlations of expenditures, savings, and whether a household is indebted or not, the latter does not seem to be correlated with adoption behavior.

While we do not find evidence for a robust association between household business and MGP service - most certainly due to little variation in business ownership, with only $8.4 \%$ running their own business in our pre-treatment survey - there is strong empirical support that more entrepreneurially minded households are more likely to sign up for solar microgrids. When the entrepreneurial index goes up by one unit, the odds of adoption increase by $19-26 \%$.

Our data allows us to distinguish between the effects of entrepreneurship 
and risk aversion on adoption behavior. As reported above, there is considerable evidence that business aspirations matter, whereas we do not find such an effect for risk aversion. Coefficients for risk aversion are consistently negative across models (that is, smaller than 1 in odds-ratio models), but fail to become statistically significant. This effect cannot be attributed to too little variation in our risk-aversion measure (Binswanger, 1980), with a third of our respondents being classified into the most risk-loving category. Substantively, we surmise that this result, which contrasts with some of the earlier literature, is driven by respondents in our sample having a good understanding of solar technology already. After all, the benefits of the MGP service are easy to demonstrate and entail little uncertainty, at least far less as when compared to high-yield fertilizers or more complex technical solutions. For example, more than 7 out of 10 villagers in the study knew someone using solar power and the vast majority of respondents answered that solar power improves both the quality (98.7\%) and reliability (96.6\%) of lighting. This suggests that risk aversion resulting from uncertainty about the benefits from the technology on offer is unlikely to be an impediment to technology adoption for well understood and established technologies (Duflo et al., 2008).

The null results on different types of trust are also interesting. If anything, the exponentiated coefficient is below 1: higher levels of trust in companies and people in the habitation are associated with lower likelihood of technology adoption. However, the confidence intervals around the estimates are so wide that in both cases the $95 \%$ confidence intervals cover the odds ratio of 1 . Given this uncertainty, the most natural interpretation is that variation in trust cannot explain technology adoption decisions. Although both abuse and other forms of non-cooperative behavior are possible in principle, in practice households do not see these threats as serious concerns. This is consistent with the notion that MGP has been successful in preventing abuse in the form of power theft or use of unauthorized devices.

Turning attention to the subsample of habitations in which MGP ultimately ended up installing solar microgrids, we find results that mirror the ones presented above. Although statistical significance attenuates for some coefficients due to a $50 \%$ reduction in sample size, we qualitatively come to the same conclusions regarding the factors that affect technology adoption. Household expenditures, savings, and entrepreneurship are the most critical determinants.

Control variables, by and large, do not have strong effects on the adop- 
tion of solar microgrids. While kerosene expenditures on the private market are estimated to positively affect adoption, as expected, standard errors are typically large, which prevents us from rejecting the null hypothesis of no effect of prior fuel expenditures and solar microgrid adoption. The wide confidence intervals are however not too surprising as households with larger expenditures have a preference for higher energy consumption, driving down marginal utility less quickly. This unobserved heterogeneity adds uncertainty to our estimates. Further, even after adoption, MGP's solar service will not be sufficient to meet a household's energy demand due to the microgrids' limited scope. Households will therefore continue consuming kerosene, which should weaken the association between kerosene expenditures and microgrid adoption.

Larger households and households with better educated household heads seem to be less likely to adopt solar microgrids, pointing at possible limitations of the MGP service especially for households with many members, most likely due to the small scale nature of the lighting technology offered. Backward caste households seem to be more likely to adopt when we look at the full sample, but this effect goes away once we condition on the subsample in which microgrids were installed. Descriptive statistics in Appendix A3 (Table A6) also show there is no systematic relationship between technology adoption and habitation level caste composition. Indeed, out of the 25 habitations with MGP microgrids, 9 consist of only backward caste households, 3 are exclusively scheduled caste households, while the remaining 13 have a mixed caste composition. ${ }^{17}$ Positive attitudes towards solar power make adoption more likely: whenever households are convinced that solar power can decrease lighting cost, this increases chances for adoption.

\section{Conclusion}

We have presented a general model of household technology adoption and tailored it to the case of improved household lighting for unelectrified areas. To estimate the model and test hypotheses about patterns of tech-

\footnotetext{
${ }^{17}$ Furthermore, out of 15 homogeneously backward caste habitations, a microgrid is installed in 9 of while, while six do not adopt; similarly, for 5 scheduled caste only habitations, 3 see a system installed, but 2 do not. Several $\chi^{2}$ of installation status and caste composition measures do not allow to reject the null hypothesis that caste distributions are identical across installation and non-installation habitations.
} 
nology adoption, we have used data from a field study of solar mircogrids in rural Uttar Pradesh, India. The results from the empirical analysis highlight the importance of income effects (affordability of quality lighting) and entrepreneurial spirit (willingness to experiment with new technologies), while pre-existing lighting expenditures on the conventional lighting alternative, kerosene fuel, appear to be less important as predictors. Similarly, trust in other people in the community and companies does not predict technology adoption.

These results suggest productive directions for new research on the economics of household technology adoption. While the affordability result is broadly consistent with conventional accounts, the lack of a relationship between prior fuel expenditures is surprising and suggests that households do not view kerosene and solar power as ready substitutes. The importance of entrepreneurial spirit, but not risk acceptance, suggests that attitudes toward new technology cannot be reduced to risk aversion but instead constitute an additional dimension of technology adoption. Further developing and testing these hypotheses in other domains, such as communication technology or water-purifying equipment, would contribute to progress toward a more complete theory.

Although the relationship between household characteristics and technology adoption cannot be directly tested with experimental methods, we see several opportunities for causal identification of the effects of the relevant factors. One interesting approach would be to provide households with a technology that reduces their fuel expenditures but does not improve lighting quality, and then if they are still interested in a wholly new technology that promises better lighting quality. A behavioral economics approach could entail priming households to strengthen entrepreneurial spirit and see if such an intervention would increase technology adoption.

A useful way to interpret the results is to consider the model as a stylized presentation of the decision-making problem and then assess the empirical results in light of the significance of different parameters. Our null results on risk aversion and trust, for example, show that uncertainties surrounding the quality, durability, and other aspects of basic household technology do not appear important in the prediction of technology adoption. At the same time, model parameters related to the size of income effects and, more originally, entrepreneurial spirit are critical in this context. Theorizing about the interactions between contextual factors, the nature of the household technology under consideration, and the importance of parameters for these various 
dimensions of the problem could contribute toward the development of a full microeconomic theory of household technology adoption. As we have seen, such a theory can draw on the adoption of productive (e.g., agricultural) technology, but the relevant dimensions of the household head's problem are quite different and require a modified approach.

Our empirical application also sheds new light on expanding the adoption of off-grid solar power. The importance of entrepreneurial spirit as an explanation for variation in adoption suggests that households are interested in using improved lighting for livelihood activities. Complementary interventions, such as access to credit for business creation, could furnish benefits. We also note that improving the reliability of the energy service could help, as one-third of the customers initially subscribed to the service and then dropped it, mostly citing quality issues. Finally, we conjecture that India's

generous kerosene subsidies could artificially reduce the competitiveness of solar power as a modern alternative.

\section{Acknowledgements}

MORSEL India did an excellent job with the data collection. We thank Semee Yoon and Jeremy Weber for helpful comments.

\section{Funding}

This work was supported by the India Country Programme of the International Growth Centre, the Tata Center for Technology and Design at the Massachusetts Institute of Technology, and Smart Power India. 
Summary statistics by group

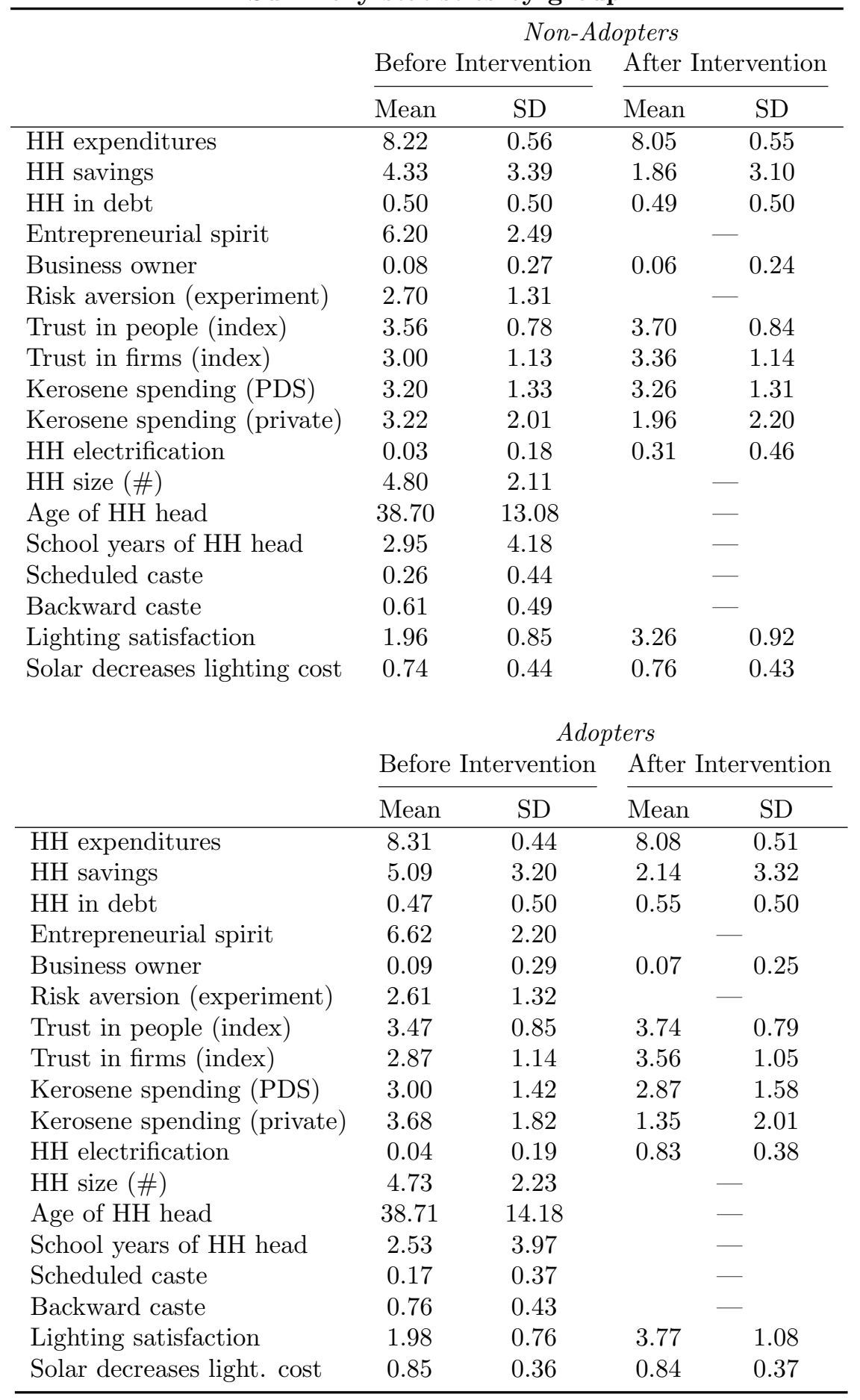

Table 7: Table 6: Summary statistics for main variables divided by adoption status and before/after actual adoption. Variables thaß3re time-invariant, slowly varying, measured only once, or where variation is not meaningful are only reported for the pre-intervention period. 
Logistic panel regressions: Technology adoption

\begin{tabular}{|c|c|c|c|c|c|c|c|c|}
\hline & \multicolumn{4}{|c|}{ Full sample } & \multicolumn{4}{|c|}{ Subsample: MGP service installed } \\
\hline & $\begin{array}{c}(1) \\
\text { Model }\end{array}$ & $\begin{array}{c}(2) \\
\text { Model }\end{array}$ & $\begin{array}{c}(3) \\
\text { Model }\end{array}$ & $\begin{array}{c}(4) \\
\text { Model }\end{array}$ & $\begin{array}{c}(5) \\
\text { Model }\end{array}$ & $\begin{array}{c}(6) \\
\text { Model }\end{array}$ & $\begin{array}{c}(7) \\
\text { Model }\end{array}$ & $\begin{array}{c}(8) \\
\text { Model }\end{array}$ \\
\hline HH expenditures (rupees/month, log) & $\begin{array}{c}2.59^{* * *} \\
(0.77)\end{array}$ & $\begin{array}{c}2.41^{* * *} \\
(0.74)\end{array}$ & $\begin{array}{c}2.29^{* * *} \\
(0.71)\end{array}$ & $\begin{array}{c}2.61^{* *} \\
(1.21)\end{array}$ & $\begin{array}{c}5.61^{* * *} \\
(3.65)\end{array}$ & $\begin{array}{l}6.33^{*} \\
(6.53)\end{array}$ & $\begin{array}{l}5.54^{* *} \\
(4.15)\end{array}$ & $\begin{array}{l}4.39^{*} \\
(3.41)\end{array}$ \\
\hline HH savings (rupees/month, log) & $\begin{array}{c}1.19^{* * *} \\
(0.06)\end{array}$ & $\begin{array}{c}1.19^{* * *} \\
(0.06)\end{array}$ & $\begin{array}{c}1.19^{* * *} \\
(0.05)\end{array}$ & $\begin{array}{c}1.22^{* * *} \\
(0.07)\end{array}$ & $\begin{array}{c}1.30^{* * *} \\
(0.12)\end{array}$ & $\begin{array}{c}1.35 \\
(0.25)\end{array}$ & $\begin{array}{l}1.31^{* *} \\
(0.15)\end{array}$ & $\begin{array}{l}1.25^{* *} \\
(0.11)\end{array}$ \\
\hline $\mathrm{HH}$ in debt & $\begin{array}{c}0.73 \\
(0.33)\end{array}$ & $\begin{array}{c}0.71 \\
(0.32)\end{array}$ & $\begin{array}{c}0.70 \\
(0.33)\end{array}$ & $\begin{array}{c}0.83 \\
(0.44)\end{array}$ & $\begin{array}{c}0.83 \\
(0.60)\end{array}$ & $\begin{array}{c}0.63 \\
(0.52)\end{array}$ & $\begin{array}{c}0.69 \\
(0.53)\end{array}$ & $\begin{array}{c}0.91 \\
(0.63)\end{array}$ \\
\hline Entrepreneurial spirit & & $\begin{array}{c}1.19^{* * *} \\
(0.08)\end{array}$ & $\begin{array}{c}1.23^{* * *} \\
(0.08)\end{array}$ & $\begin{array}{c}1.33^{* * *} \\
(0.12)\end{array}$ & & $\begin{array}{l}1.58^{* *} \\
(0.36)\end{array}$ & $\begin{array}{c}1.60^{* * *} \\
(0.22)\end{array}$ & $\begin{array}{c}1.51^{* * *} \\
(0.18)\end{array}$ \\
\hline Business owner & & $\begin{array}{c}1.13 \\
(0.75)\end{array}$ & $\begin{array}{l}1.09 \\
(0.73)\end{array}$ & $\begin{array}{c}0.82 \\
(0.71)\end{array}$ & & $\begin{array}{c}2.08 \\
(3.08)\end{array}$ & $\begin{array}{l}1.84 \\
(2.33)\end{array}$ & $\begin{array}{c}1.57 \\
(1.87)\end{array}$ \\
\hline Risk aversion (experiment) & & $\begin{array}{c}0.88 \\
(0.12)\end{array}$ & $\begin{array}{c}0.85 \\
(0.11)\end{array}$ & $\begin{array}{c}0.95 \\
(0.13)\end{array}$ & & $\begin{array}{c}0.91 \\
(0.27)\end{array}$ & $\begin{array}{c}0.89 \\
(0.23)\end{array}$ & $\begin{array}{c}1.04 \\
(0.22)\end{array}$ \\
\hline Trust in people (index) & & & $\begin{array}{c}0.74 \\
(0.17)\end{array}$ & $\begin{array}{l}0.65^{*} \\
(0.16)\end{array}$ & & & $\begin{array}{c}0.67 \\
(0.25)\end{array}$ & $\begin{array}{c}0.64 \\
(0.22)\end{array}$ \\
\hline Trust in firms (index) & & & $\begin{array}{c}0.80 \\
(0.17)\end{array}$ & $\begin{array}{c}0.74 \\
(0.18)\end{array}$ & & & $\begin{array}{c}0.86 \\
(0.34)\end{array}$ & $\begin{array}{c}0.83 \\
(0.32)\end{array}$ \\
\hline Kerosene spending (PDS, rupees/month, log) & & & & $\begin{array}{c}0.93 \\
(0.15)\end{array}$ & & & & $\begin{array}{c}1.14 \\
(0.30)\end{array}$ \\
\hline Kerosene spending (private, rupees/month, log) & & & & $\begin{array}{l}1.27 \\
(0.21)\end{array}$ & & & & $\begin{array}{c}1.25 \\
(0.27)\end{array}$ \\
\hline HH electrification & & & & $\begin{array}{c}1.28 \\
(2.03)\end{array}$ & & & & $\begin{array}{c}1.86 \\
(1.98)\end{array}$ \\
\hline HH size (\#) & & & & $\begin{array}{c}0.88 \\
(0.09)\end{array}$ & & & & $\begin{array}{c}0.84 \\
(0.13)\end{array}$ \\
\hline Age of HH head & & & & $\begin{array}{c}0.99 \\
(0.02)\end{array}$ & & & & $\begin{array}{c}0.97 \\
(0.03)\end{array}$ \\
\hline School years of HH head & & & & $\begin{array}{c}0.87^{* *} \\
(0.05)\end{array}$ & & & & $\begin{array}{c}0.91 \\
(0.07)\end{array}$ \\
\hline Scheduled caste & & & & $\begin{array}{c}1.53 \\
(2.28)\end{array}$ & & & & $\begin{array}{c}1.24 \\
(1.87)\end{array}$ \\
\hline Backward caste & & & & $\begin{array}{c}9.26^{* *} \\
(8.87)\end{array}$ & & & & $\begin{array}{c}5.42 \\
(6.27)\end{array}$ \\
\hline Lighting satisfaction & & & & $\begin{array}{c}0.21 \\
(0.35)\end{array}$ & & & & $\begin{array}{c}0.22 \\
(0.48)\end{array}$ \\
\hline Solar power decreases lighting cost & & & & $\begin{array}{c}4.21^{* *} \\
(2.68)\end{array}$ & & & & $\begin{array}{l}4.29^{*} \\
(3.56)\end{array}$ \\
\hline Observations & 1530 & 1530 & 1530 & 1530 & 784 & 784 & 784 & 784 \\
\hline Habitations & 49 & 49 & 49 & 49 & 25 & 25 & 25 & 25 \\
\hline
\end{tabular}

endent Variab

Standard errors in parentheses and clustered by habitation.

All explanatory variables are measured pre-treatment.

${ }^{*} p<0.10,{ }^{* *} p<0.05,{ }^{* * *} p<0.01$

31

Table 8: Panel models (coefficients as odds-ratios) for full sample (models 1-4) and for habitations with MGP service (models 5-8). 
Adesina, A. A., Zinnah, M. M., 1993. Technology characteristics, farmers' perceptions and adoption decisions: A tobit model application in Sierra Leone. Agricultural Economics 9 (4), 297-311.

Aklin, M., Bayer, P., Harish, S., Urpelainen, J., 2017. Does basic energy access generate socioeconomic benefits? A field experiment with off-grid solar power in India. Science Advances 3 (5), e1602153.

Aklin, M., Cheng, C., Urpelainen, J., Ganesan, K., Jain, A., 2016. Factors affecting household satisfaction with electricity supply in rural India. Nature Energy 1, 16170.

Bandiera, O., Rasul, I., 2006. Social networks and technology adoption in northern Mozambique. The Economic Journal 116 (514), 869-902.

Binswanger, H. P., 1980. Attitudes Toward Risk: Experimental Measurement in Rural India. American Journal of Agricultural Economics 62 (3), 395407.

Bollinger, B. K., Gillingham, K., 2012. Peer effects in the diffusion of solar photovoltaic panels. Marketing Science 31 (6), 900-912.

Cheng, C., Urpelainen, J., 2014. Fuel stacking in India: Changes in the cooking and lighting mix, 1987-2010. Energy 76, 306-317.

Coleman, J. S., 1988. Social capital in the creation of human capital. American Journal of Sociology 94 (Supplement), S95-S120.

Conley, T. G., Udry, C. R., 2010. Learning about a new technology: Pineapple in Ghana. The American Economic Review 100 (1), 35-69.

Cornes, R., Sandler, T., 1986. The Theory of Externalities, Public Goods, and Club Goods. Cambridge University Press, New York.

Dillon, J. L., Scandizzo, P. L., 1978. Risk Attitudes of Subsistence Farmers in Northeast Brazil: A Sampling Approach. American Journal of Agricultural Economics 60 (3), 425-435.

Dinkelman, T., 2011. The effects of rural electrification on employment: New evidence from South Africa. American Economic Review 101 (7), 30783108 . 
Doepke, M., Zilibotti, F., 2005. Social class and the spirit of capitalism. Journal of the European Economic Association 3 (2-3), 516-524.

Duflo, E., Kremer, M., Robinson, J., 2008. How high are rates of return to fertilizer? evidence from field experiments in Kenya. American Economic Review Papers and Proceedings 98 (2), 482-88.

Duflo, E., Kremer, M., Robinson, J., 2011. Nudging farmers to use fertilizer: Theory and experimental evidence from Kenya. American Economic Review 101 (6), 2350-90.

Foster, A. D., Rosenzweig, M. R., 1995. Learning by doing and learning from others: Human capital and technical change in agriculture. Journal of Political Economy 103 (6), 1176-1209.

Galor, O., Michalopoulos, S., 2012. Evolution and the growth process: Natural selection of entrepreneurial traits. Journal of Economic Theory 147 (2), 759-780.

Giné, X., Yang, D., 2009. Insurance, credit, and technology adoption: Field experimental evidence from Malawi. Journal of Development Economics 89 (1), 1-11.

Government of India, 2011. 2011 census report, houselisting and housing census data highlights, available at http://www.censusindia.gov.in/ 2011census/hlo/hlo_highlights.html.

Guiso, L., Paiella, M., 2008. Risk Aversion, Wealth, and Background Risk. Journal of the European Economic Association 6 (6), 1109-1150.

Hardin, R., 2002. Trust and Trustworthiness. Russell Sage Foundation, New York.

Holt, C. A., Laury, S. K., 2002. Risk Aversion and Incentive Effects. The American Economic Review 92 (5), 1644-1655.

Jacobson, A., 2007. Connective power: Solar electrification and social change in Kenya. World Development 35 (1), 144-162.

Katz, M. L., Shapiro, C., 1985. Network externalities, competition, and compatibility. American Economic Review 75 (3), 424-440. 
Komatsu, S., Kaneko, S., Shrestha, R. M., Ghosh, P. P., 2011. Nonincome factors behind the purchase decisions of solar home systems in rural bangladesh. Energy for Sustainable Development 15 (3), 284-292.

Koundouri, P., Nauges, C., Tzouvelekas, V., 2006. Technology adoption under production uncertainty: Theory and application to irrigation technology. American Journal of Agricultural Economics 88 (3), 657-670.

Lam, N. L., Smith, K. R., Gauthier, A., Bates, M. N., 2012. Kerosene: A review of household uses and their hazards in low- and middle-income countries. Journal of Toxicology and Environmental Health, Part B 15 (6), 396-432.

Lay, J., Ondraczek, J., Stoever, J., 2013. Renewables in the energy transition: Evidence on solar home systems and lighting fuel choice in Kenya. Energy Economics 40, 350-359.

Masera, O. R., Saatkamp, B. D., Kammen, D. M., 2000. From linear fuel switching to multiple cooking strategies: A critique and alternative to the energy ladder model. World Development 28 (12), 2083-2103.

Morris, M. G., Venkatesh, V., 2000. Age differences in technology adoption decisions: Implications for a changing work force. Personnel Psychology 53 (2), 375-403.

Olson, M., 1965. The Logic of Collective Action - Public Goods and the Theory of Groups. Harvard University Press, Cambridge, MA.

Rao, N. D., 2012. Kerosene subsidies in India: When energy policy fails as social policy. Energy for Sustainable Development 16 (1), 35-43.

Rebane, K. L., Barham, B. L., 2011. Knowledge and adoption of solar home systems in rural Nicaragua. Energy Policy 39 (6), 3064-3075.

Samad, H. A., Khandker, S. R., Asaduzzaman, M., Yunus, M., December 2013. The benefits of solar home systems: An analysis from Bangladesh, world Bank Policy Research Working Paper 6724.

Schumpeter, J., 2003 [1943]. Capitalism, Socialism and Democracy. Routledge, New York. 
Smith, M. G., Urpelainen, J., 2014. Early adopters of solar panels in developing countries: Evidence from Tanzania. Review of Policy Research 31 (1), $17-37$.

Solow, R. M., 1956. A Contribution to the Theory of Economic Growth. The Quarterly Journal of Economics 70 (1), 65-94.

Suri, T., 2011. Selection and comparative advantage in technology adoption. Econometrica 79 (1), 159-209.

Urpelainen, J., Yoon, S., 2015. Solar home systems for rural India: Survey evidence on awareness and willingness to pay from Uttar Pradesh. Energy for Sustainable Development 24, 70-78.

World Bank, 2008. The welfare impact of rural electrification: A reassessment of the costs and benefits, impact Evaluation Report by Independent Evaluation Group. 